$N V U A J M U V$
$D Q$

ENAODFECKTACTSVQDEFBN I MAr.

YKFEQLOPNGFGRGHNWEDWCYQAFVNK,

A C VBOFETZHNAXCFTJKJZMHZKXAYHASG_

TCA SN I NROAXEVEDKDLA GQSWIPRNGMDSA U M

S GEBERZYLINDERZNUR-I MB C NCAWZYKFEQLO,

$M Z G O H A S E D C K L P S Y C$ C B V V G R A K E C L Z M S r.

VCXYMLMOKNIJBWVVTQZTEFNAXJRCNIFZKM,

CRFVEGBZHNUJN URTLVVVHNVUAJKUVXESYM,

NWA SRECVFHKW $M|Q W U R T O| J E$ KHES Y S C B F GM ONCALVIKNDV VBNMIQWURTZ N J I MNSTRECL YKFED I OPNGS KGE C E Z M S A C $F X J L R N \mid F Z K M D$ N VRDJKUVXES $K Q F H B Q F G \cup P W Q$ O I ZPMRDRNQBO VWM C R M U U P I Z A KDPJPPSDFGHJ L S J T DWYKJHGF D E K J R C E O I J GRD C $M O T Y Q L G N T Z D S Q O$ $T N \cup E$ I I RLUJGD |NG DCOOVGESOPMNVCS $J Y|Z Q H A H| N C W Q Y J A$ N J KVNTRAKDOBN JORO A A O U UNDONGIUARNH UDMB B E B H M R E B P B D L $A A O F \mathbf{R}$ I C T I O N I U A R N I O $M O T M Q G G N T Z D S Q O M G D N V U L$ UDMTBH B HMGR I BDPBDLRBEFU NRZQINKOSHUZGFDG

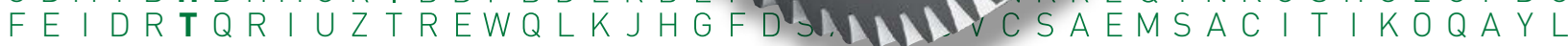
CIMNSTRECLPQACEZRWDXAYHBMWRZIRECSPLOCYQTEQTFCX $P J M N|J H L M O K N| J U H B Z G V T F C R D X E S N W K R M O K N I J B B Z G W R Z V$ C GTJDGLETUOADGJLYCBMWRZIPSFHKTVNCBFGMHTILQNVXD J T Z UETOIZRWQETUOMBCYNVXADGJLKHESIKNDVSGWJPNEDC 


\section{Light, Compact and Efficient}

\section{Schaeffler differential systems set the pace}

Thorsten Biermann

$M r_{1}$

Q SMH

$M B Q S W \mid\llcorner\cdots$

C BMBCHSEH

VTCB STPOIODCVトL。

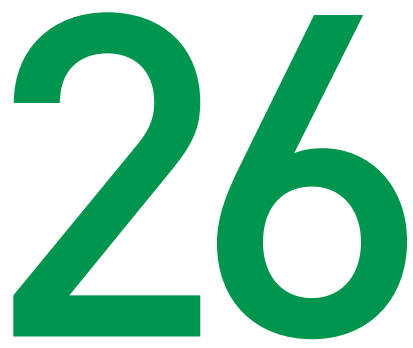

$M R \vee T Q U J X R E L K J H G F D S A \mid V_{1} \ldots$

VNMRTXAGYWPHCEQA YWS XEECK.

TFVNHOUB I JBZGVTFCRDXESNWASKL

$B P T F L U J A D G Y C B M W R Z$ I P S F H K T V N Z LMU,

SKBPORUTETMBCYNVXADGJLKHESYSCBMBし

KLSKUPOWRWZTWHNEDKUNWPONCALVIKZTWHIV

$X A K L P F L K J K O|\cup Z T R E W Q Y X C \vee B N M| Q W U O$ I U Z TR

UKXAYHASGSVNPIZRWQSCGZNJ|MNSTRVNPIZRWQ_

C ZUKOGIKCKPMNESWLNCXWZYKFEDIOPPMNESWLNCX

T S C Z G ZMQ G O D V US GRVLGRVKGECEZEMDNVUSGRVLGh OMTSLOKZ I NEXOMNYAZTEWNFX JLRN I FEXOMNYAZTEW

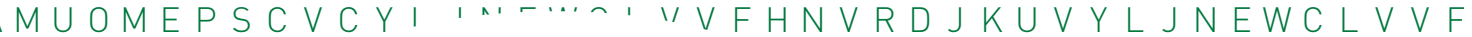
INSMUAN J Y $\cap$ '. 'SQFHBQFGOBRELNFXTJC

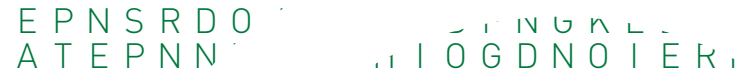

E P A T B

C Z E P P

A T C Z

$\checkmark T A$

$M R V$

VNN

T F

B P

$\mathrm{S} K$
D D LRB EFBAFVN K

. UAH I OGDNOIERNGM

$O Q O D N V \cup S G R V L G R \vee K G$

$P D B D D L R B E F B A F V N K F N r$

, OTRELKJHGFDSAMMBVCX $X A Z Y W P H C E Q A Y W S X E E C R F$ I $O \cup B$ I JBZGVTFCRDXESNWA S U JRDGYCBMWRZIPSFHKTVN $R \cup T E T M B C Y N \vee X A D G J L K H E S$ P OWRWZ TWHNEDKUNWPONCA $F L K J K O \mid U Z T R E W Q Y X C \vee B N M$ H A S E S V N P I ZRWQSCGZN J I M GIKCKPMNESWLNCXWZYKFF ' A S U S V N P I ZRWQ S C G Z N J I I KCKPMNESWLNCXWZYKF 'OXODNVUSGRVLGRVKG

1 I NEXOMNYAZTEWNF.

' $C Y L J N E W C L V \vee F H$. $\cap N \vee \cup S G R \vee L G F$ 


\section{Introduction}

The Schaeffler lightweight differential was presented for the first time at the 2010 Schaeffler Symposium in Baden-Baden, Germany [1]. At the time, the innovative aspect of the design focused on the reduced weight and smaller mounting space required for the groundbreaking differential concept. Since then, the lightweight differential has been further optimized in order to overcome the last of the concept's drawbacks in comparison to the existing bevel gear differential. During the optimization phase, the key focus has been to improve the rigidity of the differential, and reduce frictional losses in the main bearing support. A further aim was to reduce the production costs. Today, this means that there is virtually no effect on costs, at least when the differential is operated within high torque ranges. For those who have not yet come across the Schaeffler lightweight differential,

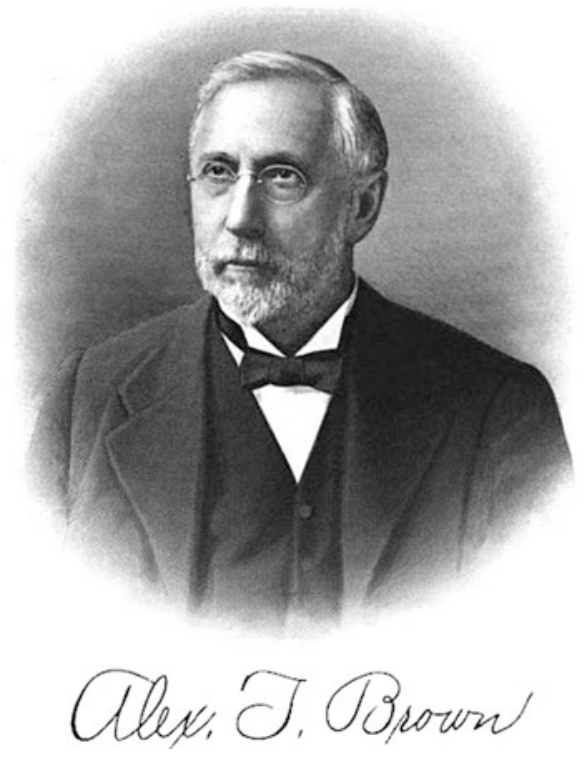

Figure 1 The father of the spur gear differential "Alexander T. Brown" what follows is a brief explanation of how the component came into existence.

Based on the most recently available sources, Alexander Timothy Brown can be described as the father of the "spur gear differential", a category of differential that includes the Schaeffler lightweight differential. Born in 1854, Brown quickly developed into a technical allrounder as well as someone "with considerable inventive talent". Yet Brown is not known for his early designs for guns or even typewriters - instead, he is known for inventing the first pneumatic tire for automotive vehicles, which he patented on December 20, 1892.

The tire wear caused by driving around bends - a problem that Brown faced when designing his new tires - may be the reason behind his invention of a new type of differential. US patent no. 691591 was granted on January 21, 1902 (Figure 2). The patent related to a design variant for a new differential as an alternative to the existing bevel gear differential. Brown's solution was to omit bevel gears in favour of spur gears - a concept made possible by designing the differential as a planetary transmission. In contrast to a conventional planetary transmission consisting of a sun gear, planet gears and a ring gear, Brown's spur gear differential did not feature ring gears. Instead, the transmission featured two output sun gears. Pairs of planet gears were then arranged around the circumference of the output sun gears. At all times, one planet gear would be meshed with the left-hand sun gear while the other planet gear would be meshed with the right-hand sun gear. The planet gears meshed with one another in the free area that remained between the gearing of the two sun gears.

The new design ensured that torque was distributed symmetrically to the wheels while still using the same number of teeth on the sun gears and planet gears. The symmetrical design also boasted a high proportion of identical parts. The closed design of the differential suggests that it was intended for use as a differential arranged coaxially to the rear axle. 


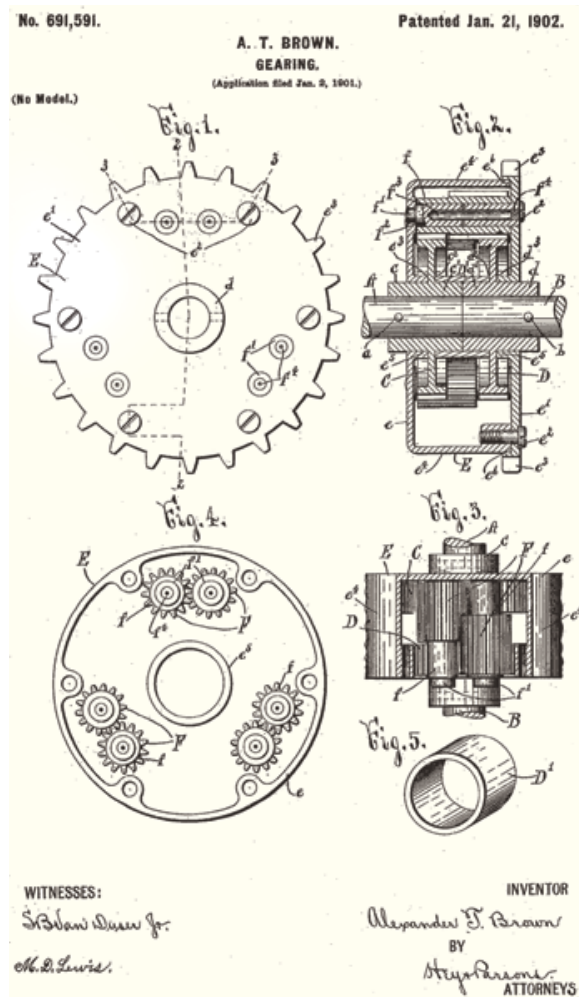

Figure 2 Excerpt from the patent specification for the first spur gear differential from 1902

\section{The Schaeffler lightweight differential}

The Schaeffler lightweight differential shares some common features with Brown's original design. Just as Brown did, the developers at Schaeffler decided to use three pairs of planet gears in the basic variant (Figure 3).

This design ensures that forces are distributed evenly across the individual contact points of the gearing, regardless of the manufacturing tolerances. The only issue was that the axial mounting space required for the original design led to problems when trying to integrate the differential into modern transmissions. With most present-day transmissions that are arranged transversely at the front of the vehicle, there is less mounting space directly next to the drive gear due to the design of the bearing seat for the output shaft or due to the position of the transmission gears. In comparison to Brown's spur gear differential, this problem meant that a more axially compact solution had to be found. The engineers were able to find the solution by further developing the compensation gearing of the differential. In contrast to Brown's design, the Schaeffler lightweight differential uses two sun gears in different sizes [2]. As one planet gear from each pair of planet gears is now arranged around a larger pitch diameter, it has been

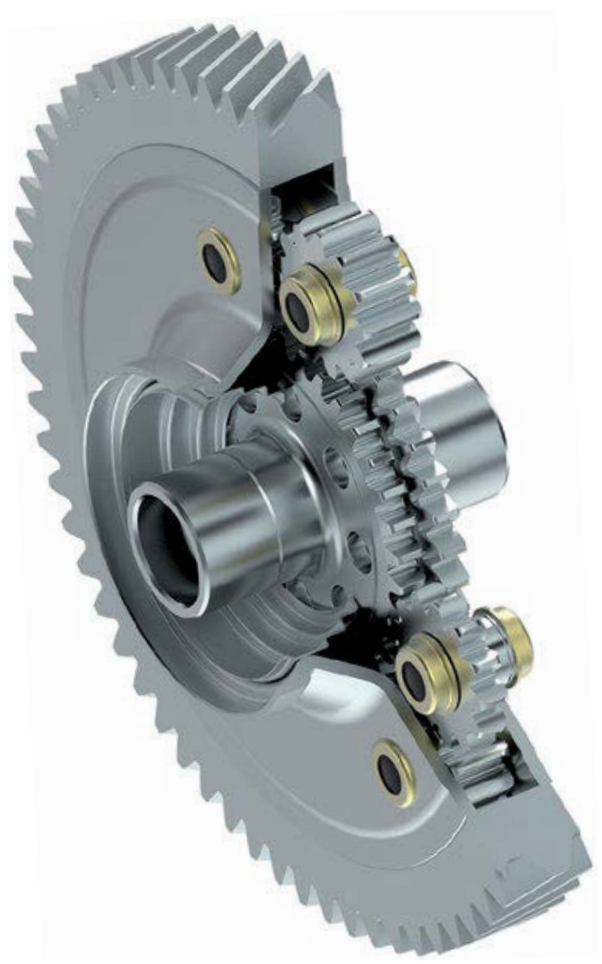

Figure $3 \quad$ Lightweight differential 


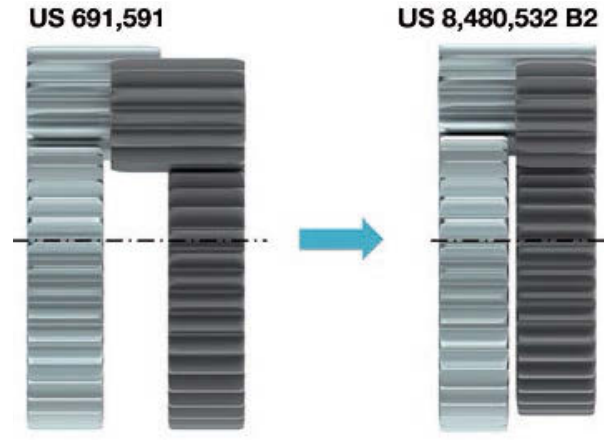

Figure 4 Transmission diagrams of the differential variants by Brown and Schaeffler

possible to shift the contact point between the gearing of the planet gears to the smaller sun gear. In contrast to Brown's patent, the Schaeffler lightweight differential therefore features only two levels of gearing instead of three. This design means a significantly smaller axial mounting space is required. The differential remains in the mounting space of the drive gear and can replace the previously used bevel gear differential without damaging any surrounding structures (Figure 4).

Figure 5 shows the gearing as viewed from the side and reveals the idea behind the new design for the sun gears.

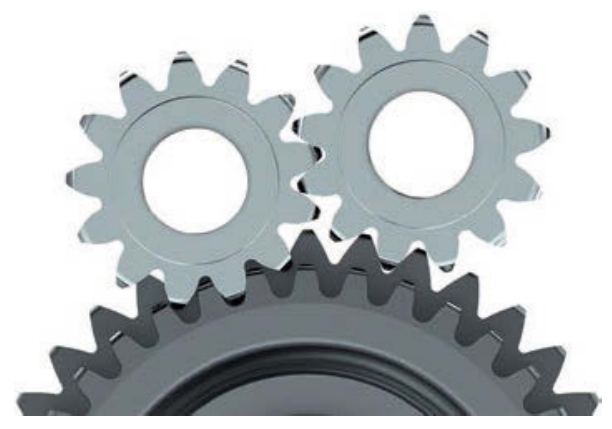

Figure 5 Side view of the compensation gearing
There is a difference in size between the two sun gears, despite the fact that they have the same number of teeth. This difference is due to the differing profile displacement of the gearings. The smaller sun gear has an extremely negative profile displacement. The area of the involute found directly at the base circle of the gearing is used. The larger sun gear has an extremely positive profile displacement. Here, the area of the involute that is furthest away from the base circle is used. The teeth of the larger sun gear have a pyramid-shaped cross section with a wide tooth root. On the smaller sun gear, the tooth root is comparatively narrow. This design leads to a higher load being placed on each tooth root on the smaller sun gear. The smaller sun gear must therefore be slightly wider than the larger sun gear. As both sun gears have the same number of teeth as well as the same module, both gearings have the same base circle diameter. The same tangential forces are applied, meaning identical torques are produced at the two sun gears. Despite the asymmetric design of the compensation gearing, the torque is therefore distributed symmetrically to the side shafts. This being the case, equation 1 applies to the internal transmission of the differential:

$$
i=-\frac{Z_{p l 1}}{Z_{s u 1}} \cdot \frac{Z_{p l 2}}{Z_{p l 1}} \cdot \frac{Z_{s u 2}}{Z_{p l 2}}=\frac{Z_{s u 2}}{Z_{s u 1}}=-1
$$

Nevertheless, the number of teeth on the planet gears does not necessarily need to be identical, as they cancel each other out in the equation. In fact, the number of teeth on the narrower planet gears can therefore be slightly larger in order to optimize the contact point between the gearing of the planet gears. For example, a larger number of teeth can increase the contact ratios without the radial mounting space having to be enlarged. 
Alternatively, there is also a solution that uses different numbers of teeth on the sun gears. In this case, the difference in the number of teeth must be calculated such that the system can still be mounted. In contrast to profile displacement, a change in the number of teeth on the sun gears actually has an impact on torque distribution, meaning that any adjustment to the number of teeth must be matched by a corresponding transmission between the planet gears. This is only made possible by using a stepped planet gear.

In equation 2, only the number of teeth on the second planet gear is canceled out. A possible solution for a differential with three pairs of planet gears would be to have one sun gear with 36 teeth, a second sun gear with 33 teeth, and a stepped planet gear with either 11 or 12 teeth.

$$
i=-\frac{Z_{p l 1 a}}{Z_{s u 1}} \cdot \frac{Z_{p l 2}}{Z_{p l 1 b}} \cdot \frac{Z_{s u 2}}{Z_{p l 2}}=\frac{Z_{s u 2}}{Z_{s u 1}}=\frac{Z_{p l 1 a}}{Z_{p l 1 b}} \cdot \frac{Z_{s u 2}}{Z_{s u 1}}=-1
$$

Another possibility would be to use different modules in the compensation gearing of the differential. This would be possible using the same or a different number of teeth on the sun gears. The latter variants perform worse than the former variants at least in terms of costs at the present time due to the stepped planet gears. As a result, the latter variants are not currently being pursued.

What all of these variants have in common, however, is their extremely narrow design in comparison to the existing gearings of bevel gear differentials. This narrow design is primarily a result of the increased number of gearing contact points. On the bevel gear differential, there are four gearing contact points between the differential pinions and the output bevel gears as standard. In contrast, torque on the lightweight differential featuring three pairs of planet gears is transferred to the two sun gears via three contact points each, creating a total of six gearing contact points.
In addition, a fundamental mechanical law also has an effect on the lightweight differential: Torque equals force times the length of the lever arm. On the spur gear differential and the bevel gear differential, the distance of the gearing contact point to the center of the differential is equal to the length of the lever arm. As the sun gears on the lightweight differential have a significantly larger gearing diameter than the bevel gears, the gearing forces are significantly reduced while maintaining the same torque. In conjunction with the number of gearing contact points, the relationship between the two diameters allows for a comparatively delicate gearing design. Such an optimum layout and design for a compensation gearing with a high level of power density is an essential aspect of the new differential design variant from Schaeffler.

Another key focus that required several development loops was the design of the differential housing and the bearing support. It was important to design the housing such that a high level of rigidity could be achieved at the gearing contact point of the drive gear, as well as a significant reduction in the amount of friction at the main bearing support in comparison to a bevel gear differential. At the same time, the reshaped bracket of the differential housing must not be exposed to high levels of stress. However, a fundamental issue stood in the way of these objectives: a significantly reduced distance between the bearings in comparison to the bevel gear differential. The following application examples show how it was possible to take this problem - which at first appeared to be a serious disadvantage - and transform it into an advantage. 

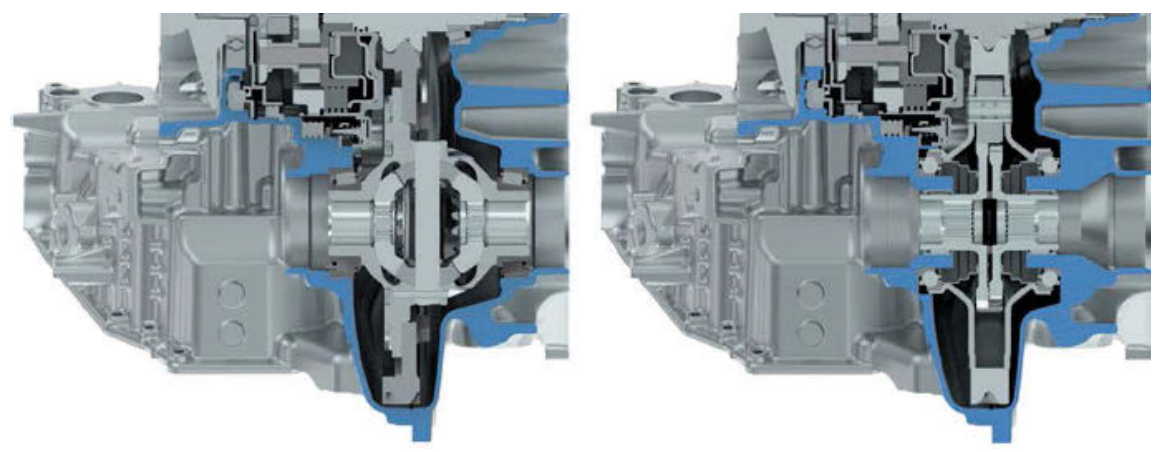

Figure 6 CVT with and without lightweight differential

\section{Current developments}

\section{Optimizing a CVT}

Figure 6 shows a continuously variable transmission (CVT) before and after replacing the traditional bevel gear differential with

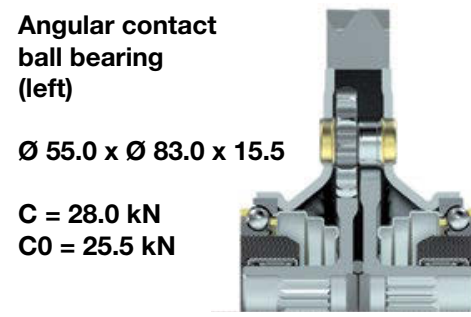

\begin{tabular}{|c|c|c|c|c|c|c|c|c|}
\hline \multirow{2}{*}{\multicolumn{2}{|c|}{$\begin{array}{l}\text { Friction } \\
2 \mathrm{kN} @ 80^{\circ} \mathrm{C}\end{array}$}} & \multicolumn{7}{|c|}{ M_diff. in $\mathrm{Nm}$} \\
\hline & & 50 & 100 & 500 & 750 & 1,000 & 1,500 & 2,000 \\
\hline \multirow{8}{*}{ 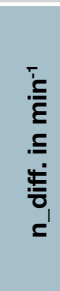 } & 40 & -0.297 & -0.293 & -0.221 & -0.220 & -0.192 & 0.001 & 0.386 \\
\hline & 100 & -0.319 & -0.316 & -0.244 & -0.241 & -0.213 & -0.021 & 0.356 \\
\hline & 200 & -0.347 & -0.345 & -0.271 & -0.271 & -0.243 & -0.057 & 0.311 \\
\hline & 400 & -0.393 & -0.392 & -0.315 & -0.317 & -0.293 & -0.118 & 0.229 \\
\hline & 600 & -0.429 & -0.428 & -0.351 & -0.354 & -0.333 & -0.166 & \\
\hline & 1,000 & -0.488 & -0.488 & -0.404 & -0.410 & -0.402 & & \\
\hline & 1,400 & -0.536 & -0.534 & -0.447 & -0.453 & & & \\
\hline & 1,900 & -0.588 & -0.586 & -0.493 & & & & \\
\hline
\end{tabular}

M_diff.: Moment of differential $\mathbf{n}$ _diff.: Speed of differential

Figure 7 Reduced drag torques through the use of angular contact ball bearings in an $\mathrm{O}$ arrangement

\section{Angular contact ball bearing (right)}

$\varnothing 55.0 \times \varnothing 83.0 \times 15.5$

$\mathrm{C}=28.0 \mathrm{kN}$

$\mathrm{CO}=25.5 \mathrm{kN}$ a lightweight differential. Despite the relalow torque capacity totaling a rated the axis, the lightweight differa total weight of $5 \mathrm{~kg}$ yet the strength of the bearing type and bearing support in comparison to the bevel gear differential. Instead of an $X$ arrangement using tapered roller bearings, two angular contact ball bearings are used in an $\mathrm{O}$ arrangement. As such, it has been possible to design the bearing support on the lightweight differential in an extremely efficient manner with regard to friction. At the same time, a long service life as well as a high level of rigidity have also been achieved. In Figure 7, the torque-dependent frictional power values of an optimized bearing sup- 
port are shown in comparison to a bevel gear differential. The green areas indicate the load scenarios in which the bearing support of the lightweight differential performs better in terms of friction in comparison to the bevel gear differential.

In the most common load scenarios, friction savings of up to $80 \%$ can be achieved, and the ball bearing support achieves an extremely high level of efficiency, even in the partial load range. This partial load range represents a key focus of conventional fuel consumption cycles. So in this application example based on the New European Driving Cycle (NEDC) it is theoretically possible to achieve fuel consumption savings of up to $0.35 \mathrm{~g}$ of $\mathrm{CO}_{2} / \mathrm{km}$ in addition to the weight saving.

\section{Optimizing a manual front transverse transmission}

The second application example (Figure 8) shows a manual transmission arranged transversely at the front of the vehicle, with

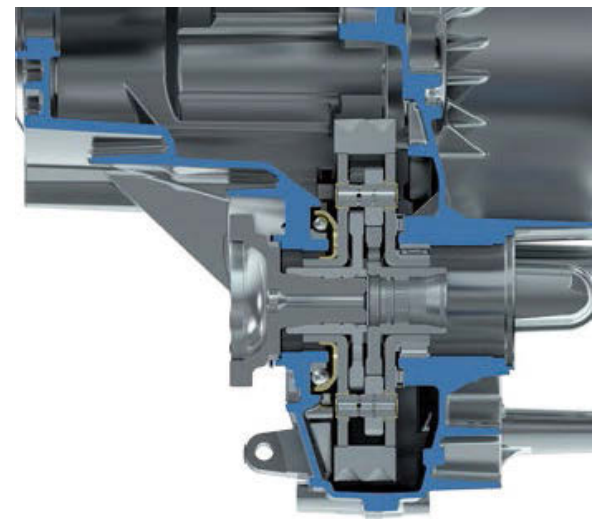

Figure $8 \quad$ Manual transmission with lightweight differential

a rated torque at axle of approximately $6500 \mathrm{Nm}$. Even at high torques upwards of $6000 \mathrm{Nm}$, thanks to the massive weight savings despite the greater number of components it is possible to eliminate any impact on costs in comparison to many existing bevel gear differentials. This remains true as long as similar volumes are produced.
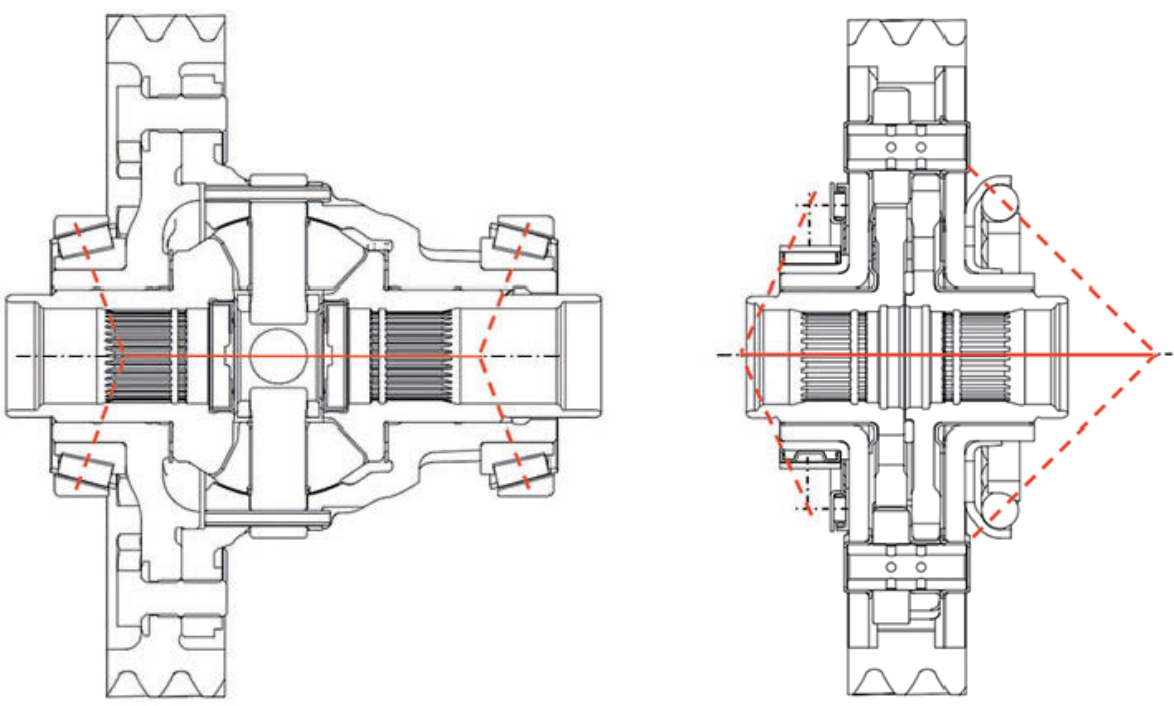

Figure 9 The bevel gear differential versus the lightweight differential: The red lines show the contact angle of the bearing support 
The reason behind this cost benefit lies in the fundamentally similar production methods used for the two differentials. The compensation gearing of the differential is extruded and the housing parts are deep-drawn while avoiding any machined rework wherever possible. In addition, the cold metal sheet forming techniques in use entail relatively low levels of energy consumption in comparison to traditional casting techniques.

Another reason behind this cost benefit is that a higher number of components may be required for the bevel gear differential in some cases: At high torques, two differential pinions are often no longer sufficient to transfer the gearing forces. Accordingly, the number of differential pinions is increased, which, in turn, requires a larger, circumferentially closed housing design.

In the present example, the weight of the bevel gear differential including the tapered roller bearing support and drive gear is equal to $13.4 \mathrm{~kg}$. The differential housing must be divided to facilitate the assembly of four differential pinions. At maximum torque peaks, the differential gearing generates expansion forces of more than $100 \mathrm{kN}$, which,

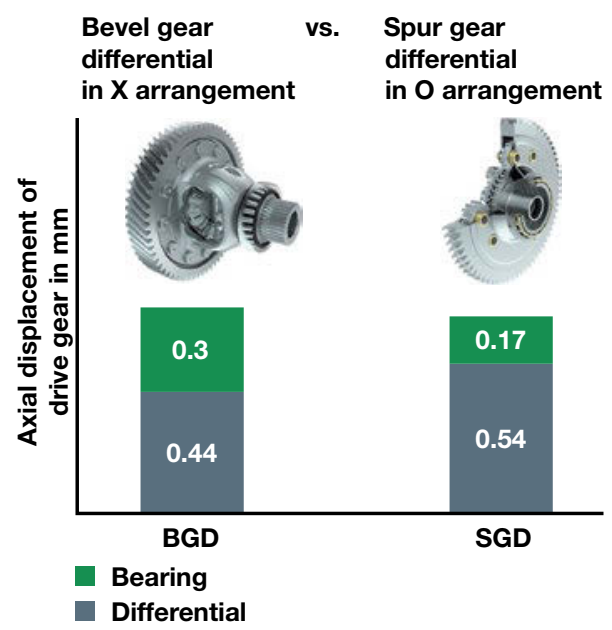

Figure 10 Rigidity measurement in addition to the torque, act upon the screw connection between the differential cage and the axle drive gear. Despite the high operating weight, there is therefore no real potential to increase the life of the overall system. As a result, it is difficult to imagine increasing the torque or even reducing the weight.

Despite the high torque, the developers at Schaeffler increased the number of pairs of planet gears in the lightweight differential to a total of four in order to keep the differential under the mounting space of the drive gear. Both halves of the housing are pressed completely into the drive gear and are riveted at four points between the pairs of planet gears in order to optimally support the drive gear (Figure 11).

In addition to stabilizing the bearing support, the flanges on the differential housing are used to center and guide the output sun gears and side shafts. Hardened sleeves are pressed into the flanges. These sleeves are fitted with corresponding oil reservoirs. Both the sun gears and the bevel gears are extended beyond the housing. As the sun gears are also fitted with internal sealing caps, the stub shafts can be disassembled without the risk of losing any oil.

Thanks to a combination of roller bearings and axial needle roller bearings, plus a new type of flange bearing, the bearing support offers an extremely high level of rigidity. The flange bearing relies on manufacturing technology similar to that used for clutch release bearings or strut bearings.

Figure 10 shows a comparison of results for current prototypes. The lightweight differential has a more deflected shape, yet this is then offset by a more rigid bearing support. The results are generally at the same level for both transmission variants, yet show the level of displacement of a drive gear riveted to the differential. The next step in the development process represents a departure from this principle towards the use of a laser welded 


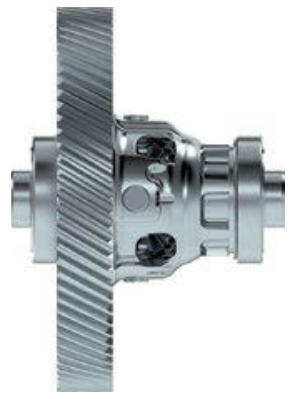

Initial situation 13.4 kg

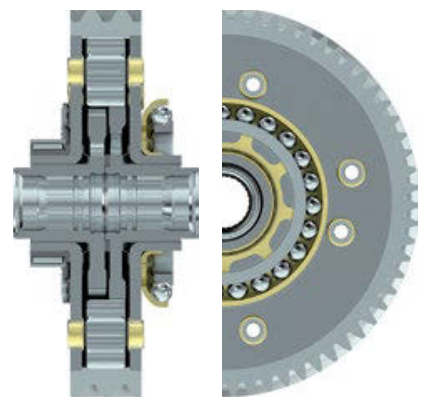

Variant A (welded) $9.1 \mathrm{~kg}$

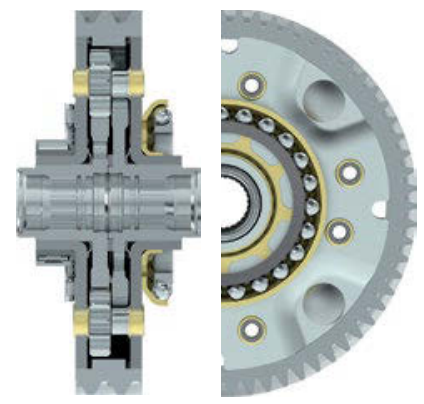

Variant B (riveted) $9.6 \mathbf{~ k g}$

Figure 11 Weight savings at high torque classes

connection, as is already used in the volume production of various bevel gear differentials. Using a welded connection creates an additional weight saving of approximately $500 \mathrm{~g}$ in comparison to the riveted variant.

Furthermore, the design of the drive gear is significantly simplified and the rigidity of the system is further enhanced by the circumferential weld seam. These characteristics mean that the drive gear in the lightweight differential has a reduced level of displacement in comparison to that of the drive gear in the bevel gear differential.

The modified drive gear also offers the option to change the technology used for manufacturing the blank. Instead of classic forging now ring rolling can be used, which can potentially contribute to a significant cost reduction in the production of the drive wheel. Dispensing with riveting also opens the possibility of using variable three or four pairs of planet gears, depending on the torque requirement. This flexibility is very congenial for a modular system.

The alternative design for the transmission with a lightweight differential therefore creates a weight saving of around $4.3 \mathrm{~kg}$ without taking into account any optimizations made to the transmission housing itself (Figure 11).

In conjunction with an optimum design for the bearing support, the weight saving corresponds to a maximum saving of around $0.6 \mathrm{~g}$ of $\mathrm{CO}_{2} / \mathrm{km}$. The use of the axial needle roller bearing support has relatively little effect when it is positioned on the coast side (Figure 12).

Both application examples show how the lightweight differential from Schaeffler can help to reduce weight and fuel consumption. The weight saving of almost more than $4 \mathrm{~kg}$ can also help to significantly reduce the total weight of the transmission. By considerably reducing the mounting space required, new free space is created for the design of the bearing support, which enables reductions in friction of up to $80 \%$ in the partial load range. The lightweight differential is also increasingly attractive when it comes to costs. In principle, similar costs to those associated with previous solutions can therefore be expected for high-volume manufacturing.

One disadvantage of the described solutions is simply the scope of application limited to transverse transmissions. For this reason, both new and familiar solutions for cost-optimized differentials or even those with an extremely high level of power density are considered in the following section. The purpose of taking a closer look at these solutions is to expand the portfolio of differentials offered by Schaeffler. 
NEDC driving cycle

- Maximum reduction in fuel consumption:

$0.025 \mathrm{l} / 100 \mathrm{~km}$

- Maximum reduction in $\mathrm{CO}_{2}$ emissions:

$0.58 \mathrm{~g} / \mathrm{km}$

Differential Type Bearing support Arrangement

$\begin{array}{llll}\text { BGD } & 1 & \text { TRB } & X \\ \text { SGD } & 2 & \text { ACBB } & 0 \\ \text { SGD } & 3 & \text { ACBB/AX + RH } & 0 \\ \text { SGD } & 4 & \text { TRB/AX + RH } & 0\end{array}$

TRB - Tapered roller bearing

ACBB - Angular contact ball bearing

AX - Axial needle roller bearing

RH - Drawn cup roller bearing

TBB - Tandem ball bearing

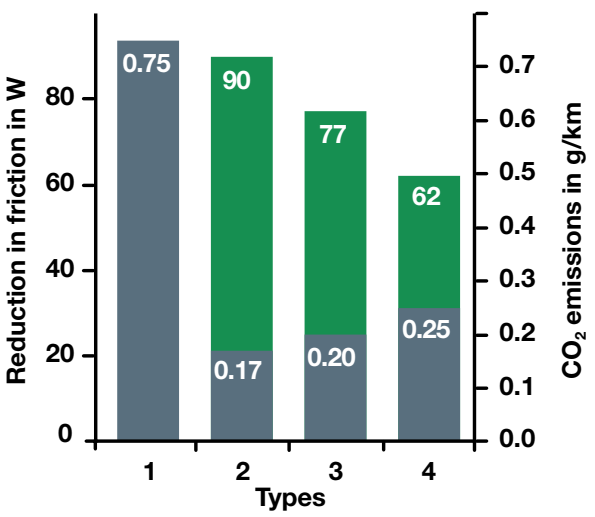

Reduction in friction

$\mathrm{CO}_{2}$ emissions

Figure 12 Reduction in fuel consumption at high torque classes

\section{The search for tomorrow's innovations}

As we have demonstrated by examining Alexander Brown's invention, an occasional look into the past can indeed be worthwhile. Sometimes, inventions from bygone eras can even highlight one approach or another that could once again prove useful with the help of modern manufacturing technology.

\section{The Wildhaber-Novikov differential}

The idea for the "Wildhaber-Novikov" differential was hit upon a few years ago when looking at the involute compensation gearing of the lightweight differential, which had only just entered into development. The project description for this differential is based on the type of gearing used for the differential pinions, which deviates from the conventional involute gearing.

An alternative circular-arc gearing had already been developed in 1926 by Dr. Ernst Wildhaber. With this gearing design, the convex teeth meshed with concave gaps and the radius of the contact points were approximately the same. In 1956, this gearing design was revisited and refined by Dr. Mikhail Novikov, a Soviet developer and military officer. In general, a higher level of power density is attributed to this gearing design than to comparable involute gearings, and its use in various military vehicles not only in the former Soviet Union has certainly contributed significantly to the reputation of the gearing design.

The developers at Schaeffler then hit upon the idea of accommodating the size difference between the sun gears - while keeping the same number of teeth - by using one convex sun gear and one concave sun gear instead of achieving this via profile displacement, as is the case on the lightweight differential. This principle is explained in Figure 13.

Using this solution, it is possible to shift the gearing contact point between the concave and convex differential gears via the smaller concave sun gear, as is also possible on the lightweight differential. The aim is to create a differential gearing that exhibits an extremely high level of power density as well as narrow radial dimensions. A design of this type could provide a solution for a differential featuring bevel gearing, for example. However, in this case the radial dimensions for the compensation gearing are limited, meaning the traditional gearing featured in the light- 

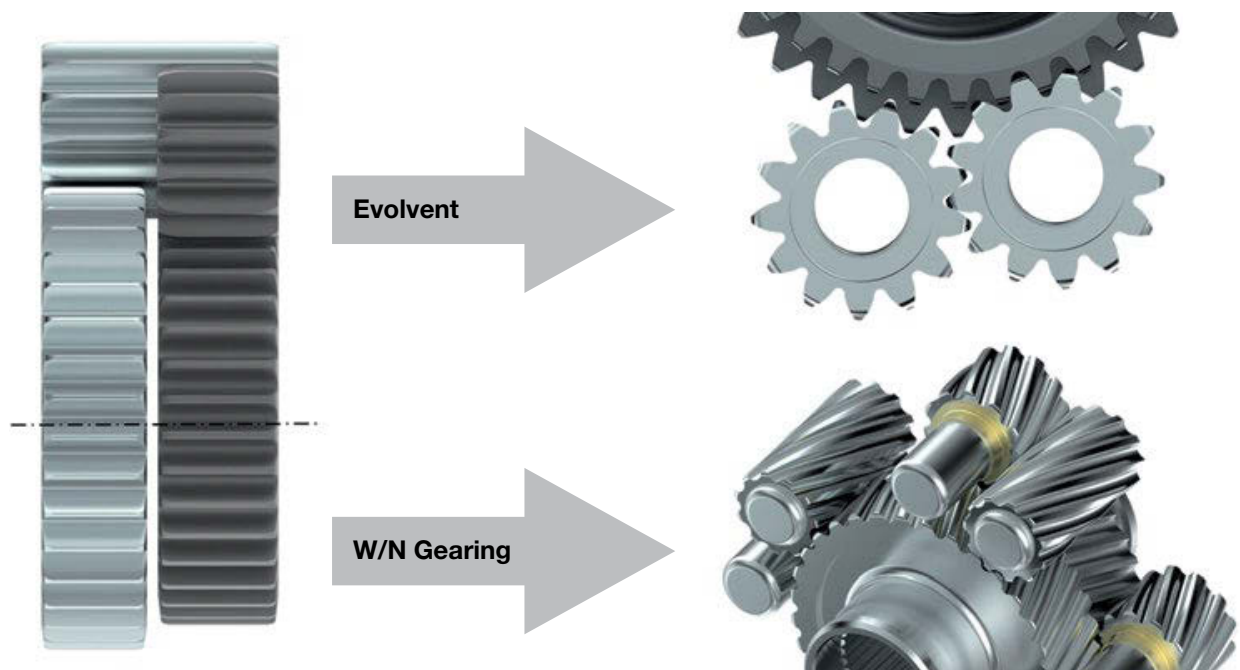

Figure 13 Asymmetric gearing on the basis of the involute and the circular-arc profile

weight differential can no longer be used. Although this idea appears to be pioneering at first glance, the engineers were not able to confirm that the Wildhaber-Novikov differential has a higher level of power density in previous investigations. For this reason, this approach has not proven successful to date, meaning it has been necessary to look for alternative solutions.

\section{Oliver Saari's differential}

In 1966, various solutions for differentials using a spur gear design were published under US patent no. 3,292,456; these differentials once again demonstrated a significant increase in performance in comparison to solutions already in existence (Figure 14). Inventor Oliver Saari designed the gearings for these differentials such that the compensation planet gears were not arranged in pairs - instead, all planet gears meshed with one another. As a result, the load on the gearing contact point between the planet gears is significantly reduced and the overall axial length of the gearing is shortened. Thanks

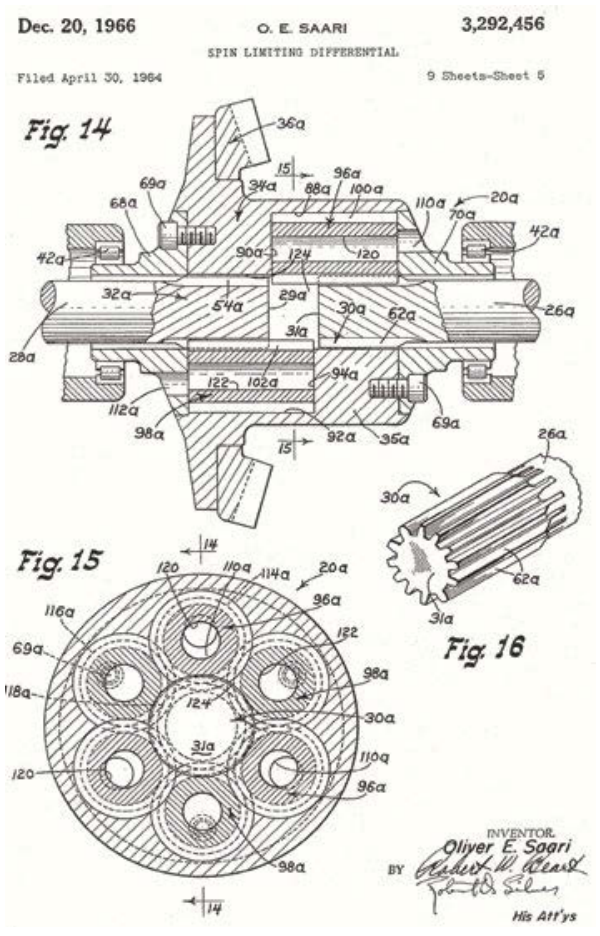

Figure 14 Excerpt from the patent specification submitted by Oliver Saari 
to the high number of gearing contact points, the gearings of the sun gears were also kept sufficiently narrow, despite narrow radial dimensions. As a result, it is possible to create a relatively compact design.

This design was of such interest to the engineers at Schaeffler that they began development of a new differential variant based on Oliver Saari's invention and in conjunction with the asymmetrical design for the sun gears. The result was the heavy-duty differential in addition to the lightweight differential from Schaeffler.

\section{The Schaeffler heavy-duty differential with all-wheel drive disconnect system}

As the provisional title would suggest, the developers at Schaeffler are currently working on a heavy-duty differential with the aim of creating a differential that has a higher level of power density than that of the existing bevel gear differential. When designing this differential, the radial mounting space requirements must still be fulfilled - unfortunately, this was not achieved with the first

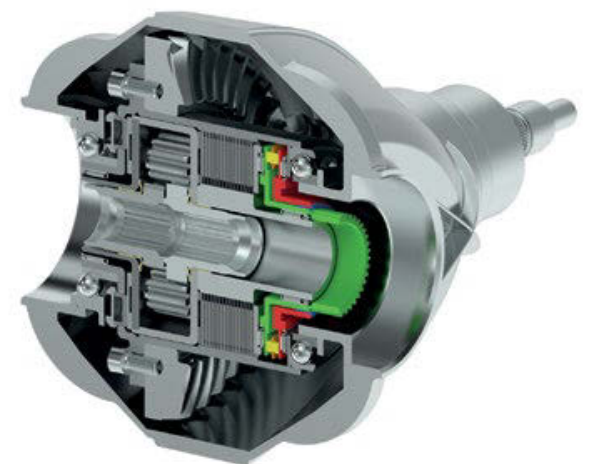

Figure 15 Heavy-duty differential with AWD disconnect system attempt with the Wildhaber-Novikov differential design. The weight and the axial mounting space required for use are less important in this particular scenario.

The development is based on the idea that the customer should not have to resort to the next largest bevel gear differential when the torque of the powertrain is increased. In this case, the customer can instead continue to use the compact heavyduty differential from Schaeffler. It is therefore also possible to indirectly create a weight saving. In addition, it is also possible to integrate features such as a differential lock or an all-wheel drive disconnect system into the extra axial mounting space.

Figure 15 shows a cross section of a heavy-duty differential featuring an additional all-wheel drive disconnect system. The all-wheel drive disconnect system in the rear-axle differential shown is used to reduce the drag torques in the powertrain by immobilizng the cardan shaft. To do this, it is not sufficient to simply interrupt the power flow to the cardan shaft in the transfer gear. Instead, it is also necessary to further separate the rear-axle differential and the wheels, as otherwise the powertrain is dragged by the rear axle.

The engineers at Schaeffler decided to perform this separation between the differential drive gear and the differential itself. To this end, the differential housing - comprising a single unit up to this point - is divided into two housings arranged coaxially to one another. The outer housing holds the axle drive gear, and the inner housing incorporates the compensation gearing. Although the differential itself is still dragged along when the disconnect system is used, it may be possible to achieve reductions in fuel consumption in the range of $5 \%$ according to a technical publication from 2009 [3].

Another distinctive feature of the Schaeffler solution is the design of the clutch unit. Although the clutch unit shown in Figure 16 may at first glance look like a conventional 


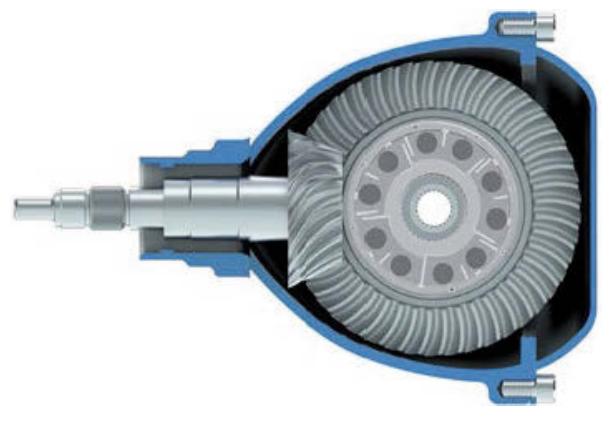

Figure 16 Cross section of the axle transmission with a self- reinforcing clutch unit

actuated wet clutch, it is in fact a one-way clutch unit actuated via additional multi-disk plates.

The use of one-way clutches on the rear axle to immobilize the powertrain is well known, and engaging the rear axle is a relatively straightforward procedure. As soon as engine speed is applied to the cardan shaft and the wet clutch is actuated, the rear axle is "overtaken" and the one-way clutch is locked. On a simple one-way clutch, the manner in which the rear axle is engaged by the prior actuation of the wet clutch is unfavourably abrupt. However, in the case of the Schaeffler solution, engagement of the rear axle is damped and only possible if the one-way clutch is being actuated by the wet clutch. The clamping function of the one-way clutch facilitates a significantly higher torque capacity than that of a comparable wet clutch. In forward direction the wet clutch is only being used as an actuation system.

As soon as the engine speed at the cardan shaft falls under the specified speed, the one-way clutch is disengaged when the wet clutch is not actuated and the drive wheel comes to a stop based on the friction at the cardan shaft. As the high torques in traction mode are absorbed by the integrated "sprag plates" and only the torques in reverse gear or in overrun mode need to be dealt with by the wet clutch, the clutch unit can be designed for an extremely high level of power density. Both the axial and radial mounting spaces are therefore compact enough to allow the distance between the bearings in the original bevel gear differential to be retained.

\section{Conclusion}

Sometimes, the key to the future lies in the past. An in-depth examination of the ideas and concepts from the pioneering age of automobiles and their relationship to today's state of the art can provide a starting point for innovations that can solve presentday problems. Current developments at Schaeffler show the way forward, helping to increase customer benefits and find answers to pressing questions relating to aspects such as lightweight construction, costs and $\mathrm{CO}_{2}$ emissions.

\section{Literature}

[1] Smetana, T.; Biermann, Th.; Hoehn, B.; Kurth, F.: Schaeffler lightweight differentials. $9^{\text {th }}$ Schaeffler Symposium, 2010, pp. 94-105

[2] Smetana, T.; Biermann, Th.: Kompakte Leichtbau-Differenziale (Compact lightweight differentials). ATZ (Automobiltechnische Zeitschrift - Automotive journal) 2/2011, pp. 108-113

[3] Gassmann, T.; Schwekutsch, M.: Verringerung des allradbedingten Mehrverbrauchs durch dynamische Allradabschaltung. ATZ 9/2009, p. 672

Open Access. This chapter is distributed under the terms of the Creative Commons Attribution Noncommercial License, which permits any noncommercial use, distribution, and reproduction in any medium, provided the original author(s) and source are credited. 